ARTIGOS

ESPAÇO, ECONOMIA E POPULAÇÃO

\title{
OS INVESTIMENTOS DOS FUNDOS DE PENSÃO BRASILEIROS NO MERCADO IMOBILIÁRIO COMERCIAL: UMA ANÁLISE DO PORTFÓLIO IMOBILIÁRIO E SEU PADRÃO TERRITORIAL
}

\author{
Maira Magnani* \\ Daniel Sanfelici* \\ Guilherme A. Muniz Filho* \\ *Universidade Federal Fluminense, Programa de Pós-Graduação em Geografia, Núcleo de Pesquisas sobre \\ Pactos Político-territoriais e Desenvolvimento, Niterói, RJ, Brasil
}

\begin{abstract}
Resumo
Considerando a necessidade de compreender de maneira mais atenta os agentes financeiros e urbanos, neste artigo, examinamos a condição de investidor imobiliário dos fundos de pensão brasileiros. Para tanto, analisamos o portfólio imobiliário dos fundos de pensão brasileiros, reconstituindo as recentes discussões sobre o investimento desse agente em tal classe de ativos e abordando os aspectos regulatórios que circundam suas práticas e alocações. Buscamos, ainda, caracterizar o patrimônio imobiliário dos fundos de pensão: quais os principais canais de investimento utilizados, bem como os segmentos e localizações investidas. A partir dos dados coletados, concluímos que há novos movimentos em favor de investimentos imobiliários conduzidos por meio de veículos financeiros; contudo, esses investimentos possuem características muito semelhantes aos investimentos adquiridos pela compra direta do imóvel comercial. Ambos os canais de investimento - direto e indireto -, como argumentamos, resultam em imóveis para uso comercial (como shopping centers e escritórios), localizados nos estados onde o mercado imobiliário comercial é bem desenvolvido, São Paulo e Rio de Janeiro.
\end{abstract}

\section{Palavras-chave}

Fundos de Pensão; Mercado Imobiliário Comercial; Investimento Imobiliário; Financeirização; Agentes Financeiros. 


\author{
ARTICLES \\ SPACE, ECONOMY AND POPULATION
}

\title{
THE INVESTMENTS OF BRAZILIAN PENSION FUNDS IN THE COMMERCIAL REAL ESTATE MARKET: A PROPERTY PORTFOLIO ANALYSIS AND ITS TERRITORIAL PATTERN
}

\author{
Maira Magnani* \\ Daniel Sanfelici* \\ Guilherme A. Muniz Filho* \\ *Universidade Federal Fluminense, Programa de Pós-Graduação em Geografia, Núcleo de Pesquisas sobre \\ Pactos Político-territoriais e Desenvolvimento, Niterói, RJ, Brazil
}

\begin{abstract}
Considering the need to understand financial and urban agents more attentively, in this article we propose to examine the condition of real estate investors of Brazilian pension funds. To this end, we examine the pension funds' real estate portfolio, review the recent discussions involving the agent's investment in this asset class and address the regulatory aspects surrounding these practices and allocations. We also sought to characterize the real estate assets of pension funds: what are the main investment channels used, as well as the segments and sites invested. We concluded that there are new movements in favor of real estate investments conducted through financial vehicles, but that these investments, however, have characteristics very similar to those acquired through the direct purchase of commercial real estate. Both investment channels, as shown in the article, result in real estate for commercial use (such as shopping malls and offices) and are located in the states whose commercial real estate market is better developed, São Paulo and Rio de Janeiro.

Keywords

Pension Funds; Commercial Real Estate Market; Real Estate Investment; Financialization; Financial Agents.
\end{abstract}




\title{
OS INVESTIMENTOS DOS FUNDOS DE PENSÃO BRASILEIROS NO MERCADO IMOBILIÁRIO COMERCIAL: UMA ANÁLISE DO PORTFÓLIO IMOBILIÁRIO E SEU PADRÃO TERRITORIAL ${ }^{1}$
}

\author{
Maira Magnani \\ Daniel Sanfelici \\ Guilherme A. Muniz Filho
}

Introdução

A década de 1980 marcou o início de um processo de integração entre mercados financeiros e produção imobiliária. O termo "financeirização" foi cunhado para traduzir as mudanças oriundas da participação ou influência de diferentes atores financeiros em esferas de atividades não financeiras, incluindo o modo como o ambiente urbano é produzido. Embora reconheçamos o grande avanço que a literatura urbana mostrou ao incorporar ao debate tal encontro (ROLNIK, 2013; HALBERT; ATTUYER, 2016; KLINK; BARCELLOS, 2017; AALBERS, 2019), ressaltamos que ainda há muito a ser investigado acerca das formas pelas quais os agentes financeiros, em suas especificidades de atuação, interagem na produção e gestão da propriedade imobiliária, de como seus investimentos são realizados e de que modo repercutem sobre a morfologia urbana.

Como mostram estudos atuais, a atuação de investidores financeiros - como fundos de pensão - no mercado imobiliário global é fruto de uma ampla reconfiguração das estratégias de investimento desses agentes, que viram um rápido crescimento de suas reservas na década 1980, sendo obrigados a selecionar novas categorias de ativos para compor seus portfólios (CLARK, 2000; HEBB; SHARMA, 2014).

\footnotetext{
1. Agradecemos ao Lincoln Institute of Land Policy e à Fundação Carlos Chagas Filho de Amparo à Pesquisa do Estado do Rio de Janeiro (Faperj) pelo financiamento da pesquisa desenvolvida neste artigo, por meio de bolsa de mestrado. À UFF, pelo financiamento ao projeto "A gestão do patrimônio imobiliário pelos fundos de pensão brasileiros: concepções, lógicas de ação e dinâmicas territoriais urbanas”, via Edita de Fomento à Pesquisa 2017 (Fopesq). Finalmente, aos revisores anônimos, pelas valiosas contribuições.
} 
A entrada de novos atores no mercado de locação foi impulsionada pela criação de veículos de investimento e pelo processo de securitização de ativos (LEYSHON; THRIFT, 2007), que possibilitaram uma mudança na forma como os mercados globais de dívida imobiliária são organizados, facilitando, em última instância, a participação de investidores financeiros e corporativos no mercado imobiliário comercial global (HALBERT et al., 2014; LIZIERI; PAIN, 2013).

Reconhecendo a importância que o imobiliário comercial tem assumido no desenvolvimento das cidades (WIJBURG; AALBERS, 2017), bem como as implicações das decisões dos agentes envolvidos nesse mercado sobre o "modo como o ambiente urbano construído se desenvolve e evolui” (THEURILLAT et al., 2010 - tradução nossa), neste artigo, procuramos esmiuçar a atuação de um agente financeiro em especial: os fundos de pensão. Esses atores concentram altas reservas de dinheiro - no caso brasileiro, beirando 1 trilhão de reais (ABRAPP, 2019a) - e destinam parte delas para o imobiliário comercial, na tentativa de encontrar ativos diversos e condizentes com seus compromissos futuros (CLARK, 2000). Nos últimos anos, os fundos de pensão entraram em cena como figuras centrais no setor imobiliário (VAN LOON; AALBERS, 2017), sendo que, no Brasil, especificamente, esses atores possuem considerável capacidade de investimento (FIX, 2007).

Considerando a necessidade de compreender de maneira mais atenta os agentes financeiros e urbanos, neste artigo, examinamos a condição de investidor imobiliário dos fundos de pensão. Para tanto, analisamos o portfólio imobiliário dos fundos de pensão brasileiros, as discussões sobre seus investimentos nessa classe de ativos e, também, os aspectos regulatórios pertinentes às suas práticas e alocações no mercado de propriedades comerciais. Buscamos caracterizar o patrimônio imobiliário dos fundos de pensão - os principais canais por eles utilizados, os segmentos e localizações investidas - e os novos movimentos e regulações em favor de investimentos imobiliários conduzidos por meio de veículos financeiros. Tal análise se insere em um contexto positivo para o crescimento dos fundos de pensão como investidores institucionais e, consequentemente, como agentes responsáveis pela reconfiguração espacial e geográfica da cidade. Em especial, no contexto brasileiro, a recente baixa da taxa de juros e a resolução do Conselho Monetário Nacional $n^{0} 4.661 / 2018$ que impede o investimento direto em imóveis (via compra de empreendimentos) põem o imobiliário como uma categoria de investimento em destaque. Essas questões serão discutidas utilizando como metodologia: (1) análise e mapeamento do portfólio imobiliário dos 10 maiores fundos de pensão brasileiros nos últimos três anos; (2) análise de documentos (regulações do setor e material de imprensa especializada); (3) observação participante de eventos e congressos promovidos pelos fundos de pensão e pela indústria financeira envolvida com seus 
investimentos; (4) entrevistas com gestores de fundos de pensão e intermediários financeiros ligados à gestão das carteiras imobiliárias dos principais fundos de pensão do país. Além disso, abordamos os resultados preliminares de uma pesquisa mais abrangente que objetiva compreender a tomada de decisão - referente aos investimentos imobiliários - dos fundos de pensão.

$O$ artigo é dividido em três seções: na primeira, fazemos uma breve revisão da literatura sobre a atuação dos fundos de pensão no mercado imobiliário comercial; na segunda, abordamos os marcos legais que disciplinam o investimento dos fundos de pensão no mercado imobiliário comercial e apresentamos discussões e pautas que incidem sobre a atual aplicação desses agentes no mercado imobiliário comercial; na terceira, discutimos os principais resultados da análise do portfólio imobiliário dos fundos de pensão brasileiros, ressaltando as localidades, os segmentos e os canais de investimento por eles mobilizados, assim como a distribuição desses investimentos imobiliários no território nacional. Finalmente, concluímos com algumas implicações econômicas e urbanas dos resultados da pesquisa.

\section{Fundos de pensão e imobiliário: breve análise da literatura}

Nos últimos anos, uma extensa literatura internacional vem se dedicando a perscrutar as repercussões econômicas e territoriais da participação de investidores financeiros no mercado imobiliário comercial. Essas pesquisas apontam, em geral, para uma difusão de métricas, racionalidades e técnicas de cálculo próprias do mercado financeiro para as atividades de produção, gestão e avaliação do estoque imobiliário comercial, com implicações sobre os tipos de empreendimentos que são produzidos, sua localização territorial e seus impactos econômicos (para uma síntese, ver AALBERS, 2019). No entanto, são mais escassos os trabalhos que se debruçam especificamente sobre os fundos de pensão, que se diferenciam de outros agentes financeiros no que se refere ao horizonte de investimento e à propensão ao risco. Convém, portanto, revisar brevemente alguns dos estudos que analisam a participação desses atores no mercado imobiliário comercial.

No âmbito da literatura internacional, Theurillat et al. (2010) investigaram de que maneira a financeirização alterou a atuação dos fundos de pensão no mercado imobiliário da Suíça. Nessa pesquisa, os autores identificam duas formas possíveis de os fundos de pensão investirem no segmento imobiliário: o canal direto (tradicional) e o canal indireto (financeirizado). O primeiro caso caracteriza-se pela compra direta de imóveis, isto é, pela aquisição dos direitos de propriedade do ativo, com a consequente responsabilidade sobre os custos relacionados à sua manutenção. Conforme apontam os pesquisadores, esse canal é mais aderente às práticas de fundos de pensão que possuem uma política de gestão interna (in-house) de 
investimentos imobiliários. Por sua vez, o canal indireto se define pela aquisição de participação em veículos lastreados em investimentos imobiliários. Nele, a administração e gestão dos investimentos fica a cargo do setor financeiro (THEURILLAT et al., 2010). Os estudiosos salientam, ainda, que há uma transição na forma de gerir os portfólios imobiliários: os fundos de pensão migraram gradualmente de uma política de gestão buy and hold (comprar e manter) para uma estratégia buy and manage (comprar e gerir), ou seja, introduziram a prática da gestão ativa do portfólio imobiliário. Essa gestão mais atenta às curvas de valorização dos ativos está, na visão dos autores, altamente relacionada com a transição do canal de investimento - de direto para indireto.

A hipótese de Theurillat et al. (2010) é que os dois modelos de gestão resultam em diferentes impactos ao ambiente construído: a preferência pelo canal financeirizado de investimento privilegiaria certos tipos de espaço (como centros financeiros), perfis seletivos de atores (como grandes empresas e agentes financeiros) e investimentos específicos no mercado imobiliário (como projetos passíveis de comparação e de grande escala). No entanto, os autores concluem que os fundos de pensão suíços, ao utilizarem o canal de investimento indireto, estavam procedendo de maneira similar à forma como geriam e investiam sua carteira imobiliária adquirida pela via direta. Por meio dos dois canais, havia concentração dos investimentos em imóveis de alto padrão localizados nas principais áreas urbanas do território suíço. Apesar de os investimentos no ambiente urbano realizados através dos dois canais não terem mostrado divergências significativas, os autores sustentam que a própria adoção de uma gestão de portfólio orientada por práticas e métricas financeiras alterou o modo como os investidores institucionais enxergam e aplicam no setor imobiliário.

Focalizando os investimentos de fundos de pensão (sobretudo do setor público) em projetos urbanos em áreas vulneráveis dos Estados Unidos, Hagerman e Hebb (2009) destacam as barreiras que esses fundos precisam contornar para investir nessa classe de ativos. As autoras apontam que os investimentos urbanos, classificados como “alternativos” na estratégia de alocação dos fundos de pensão, padecem de baixa liquidez e assimetrias de informação, elevando, assim, custos de transação. Para administrar tais riscos, os fundos de pensão americanos têm recorrido, cada vez mais, a intermediários financeiros que desenham e gerenciam veículos de investimento especializados em projetos urbanos. Esses intermediários utilizam estratégias diversas para potencializar ganhos e mitigar riscos, incluindo o uso de alavancagem (dívida) e o recurso a créditos tributários outorgados pelos governos municipais. Em trabalho complementar, Hebb e Sharma (2014) analisam os investimentos imobiliários (e também de infraestrutura) de fundos de pensão na Califórnia. Os autores sustentam que houve uma progressiva substituição de 
projetos conduzidos pelo poder público em favor de projetos levados a cabo por investidores financeiros. Essa substituição levou a uma maior seletividade dos investimentos, uma vez que o critério principal de escolha dos investidores institucionais passou a ser o binômio risco-retorno dos projetos. Sob esses critérios, muitas áreas que necessitariam de investimentos acabaram por ficar desassistidas.

Em análise sobre as estratégias de investimento dos fundos de pensão na Holanda, os argumentos de Van Loon e Aalbers (2017) convergem para os de Theurillat et al. (2010), ao sustentar que a financeirização reorientou as práticas dos fundos de pensão. Mediante a análise de um período pré-financeirização (década de 1980) e pós-financeirização, Van Loon e Aalbers (2017) evidenciam alterações experimentadas pelos fundos de pensão em quatro níveis de gestão imobiliária: (1) a gestão do fundo, na qual são feitas as principais decisões estratégicas sobre o tipo de investimento a ser realizado, passou a focar-se mais no binômio risco-retorno dos produtos imobiliários, em detrimento de objetivos sociais e políticos mais amplos; (2) a gestão do portfólio, que envolve a escolha de segmento imobiliário em que os recursos serão aplicados, começou a selecionar ativos mais diversificados, incluindo investimentos em carteiras internacionais; (3) a gestão dos ativos, que se trata da fase de negociação de ativos, em conformidade com o que foi decidido estrategicamente pelo fundo, deixou de avaliar o mercado imobiliário como um setor de difícil compreensão e passou a adotar medidas quantitativas que permitem a comparação de ativos imobiliários com outras classes de ativos; e (4) a gestão da propriedade imobiliária, relacionada a gestão de dia-a-dia do imóvel, incluindo relação com inquilinos etc., em que os fundos se afastaram de um relacionamento mais emocional com o ativo imobiliário adquirido e caminharam para a compreensão de que um imóvel é somente "mais um ativo" dentro da carteira de investimentos.

Na literatura brasileira, são poucos os estudos que abordam exclusivamente a atuação dos fundos de pensão no mercado imobiliário do país, como fizeram Theurillat et al. (2010) e Van Loon e Aalbers (2017) para seus contextos particulares. No entanto, certas investigações merecem destaque. Fix (2007), por exemplo, em sua pesquisa sobre a produção e o consumo do espaço urbano de São Paulo, desvenda a articulação existente entre alguns fundos de pensão, empresas de consultoria internacional e incorporadoras na construção de edifícios comerciais de alto padrão, localizados estrategicamente em regiões de grande potencial de valorização. A autora destaca que a ausência de um sistema de crédito para edificações comerciais no Brasil foi o que impulsionou a entrada dos fundos de pensão estatais como principais financiadores de empreendimentos imobiliários entre as décadas de 1980 e 1990. Nesse sentido, Fix (2007) analisa, ainda que de maneira incipiente, 
algumas preferências dos fundos de pensão estatais no momento do investimento em mercado imobiliário, tais como: (1) a aquisição de empreendimentos imobiliários com idade inferior a dez anos; e (2) a compra de participações nesses imóveis que garantem um quórum de tomada de decisão sobre assuntos condominiais. A autora também indica a incipiente participação dos fundos de pensão na concepção de instrumentos financeiros recém-criados, como os fundos de investimento imobiliários (FIIs).

Ao investigar especificamente a atuação dos fundos de pensão brasileiros no mercado imobiliário comercial, Sanfelici (2018) evidencia que esses agentes têm assumido, na gestão de carteiras imobiliárias, "uma clara tendência à prevalência de critérios de curto prazo sobre horizontes de tempo mais alargados nas práticas de administração de portfólio” (p. 225). Para o autor, os fundos de pensão brasileiros têm adotado práticas consideradas mais ativas de gestão do portfólio, aproximando-se dos demais intermediários e gestores do chamado "circuito financeiro". Nessa perspectiva, Shimbo et al. (2021) observam que tal mudança de racionalidade dos fundos de pensão está diretamente ligada à relação entre os fundos de pensão e as consultorias de gestão imobiliária internacionais: estas últimas, ao oferecerem serviços de "inteligência imobiliária”, promovem a difusão de uma racionalidade mais financeira na gestão do portfólio imobiliário dos atores para os que prestam serviços, incluindo os maiores fundos de pensão brasileiros.

\section{Atuação dos fundos de pensão no mercado imobiliário brasileiro: marcos legais e discussões recentes}

Os fundos de pensão buscam realizar investimentos no mercado imobiliário na tentativa de obter maiores retornos financeiros e diversificar seus portfólios (HEBB; SHARMA, 2014; CATTANEO PINEDA, 2011; THEURILLAT; CREVOISIER, 2013; VAN LOON; AALBERS, 2017; CLARK; MONK, 2017). Assim, "não só os retornos sobre a propriedade já não são considerados pobres, como também a propriedade está cada vez mais associada às virtudes da diversificação” (THEURILLAT et al., 2010, p. 21 - tradução nossa). A esse respeito, Wijburg e Aalbers (2017) assinalam que o imobiliário comercial se tornou uma importante saída para os investidores institucionais, na medida em que a rentabilidade de ações e títulos públicos, em um cenário de baixas taxas de juros, tendem a diminuir, comprometendo resultados que sustentem o compromisso atuarial das entidades.

Reconhecendo o papel fundamental que o segmento imobiliário assume na diversificação do portfólio dos fundos de pensão e, consequentemente, na manutenção do compromisso atuarial, procuramos, nesta seção, retratar a evolução do quadro normativo que disciplina essa categoria de investimento. Inicialmente, 
abordamos a criação e a consolidação do segmento imobiliário como categoria possível de investimento aos fundos de pensão. Para tanto, examinamos as regulamentações do setor desde a Constituição de 1988, que versou, pela primeira vez, sobre as Entidades Fechadas de Previdência Complementar (EFPC), chamadas de fundos de pensão. Analisamos as resoluções do Conselho Monetário Nacional (CMN) - órgão que disciplina a política de investimento dos fundos de pensão - de 1988 até dezembro de 2020. Em seguida, focamos as atuais pautas discutidas pelos agentes envolvidos no mercado imobiliário. Nesse sentido, apresentamos os principais resultados encontrados nas observações participantes e entrevistas realizadas, os quais indicam a importância do segmento imobiliário na carteira dos fundos de pensão e sublinham as recentes práticas que envolvem esse investimento.

Como metodologia de investigação, realizamos entrevistas semiestruturadas, centradas em três tipos de atores envolvidos no processo de seleção e gestão de ativos imobiliários em/para fundos de pensões: 1) gestores de carteiras imobiliárias de fundos de pensões (5 entrevistas); 2) stakeholders (partes interessadas) envolvidos em redes de decisão política (2 entrevistas); e 3) profissionais do mercado financeiro que mantêm relações com investidores institucionais, em particular, gestores de fundos de investimento imobiliário (8 entrevistas). Para o primeiro grupo de entrevistados, abordamos questões relacionadas à estruturação da área imobiliária do fundo de pensão (setores, fluxos e tipos de profissionais envolvidos), aos critérios que envolvem a seleção de ativos imobiliários e gestores terceiros e às mudanças geradas internamente devido a recentes alterações regulamentares, entre outros. Para o segundo grupo de profissionais, tratamos de aspectos mais abrangentes a respeito do processo de definição da agenda, da receptividade e das alterações trazidas pela resolução $\mathrm{n}^{\circ} 4.661$ e, também, dos investimentos dos fundos de pensões num contexto de queda das taxas de juro. Para o terceiro grupo, fizemos inquirições sobre: a prospecção de ativos dos fundos de pensões, a relação da empresa com investidores fundos de pensão e o que diferencia esse tipo de investidor de outras classes de investidores (indivíduos, escritórios familiares etc.).

Referente à consolidação do segmento imobiliário como categoria de investimento possível aos fundos de pensão, construímos o quadro a seguir com o intuito de facilitar a análise aos leitores. É importante ressaltar que o enquadramento em décadas não é, em todos os casos, fidedigno aos anos das resoluções; ele tem o objetivo de representar diferentes fases na política de investimento em imóveis.

Notamos, de acordo com as informações sintetizadas no Quadro 1, que o imobiliário sempre foi utilizado como categoria de investimento dos fundos de pensão brasileiros. Podemos observar fases de alta restrição e baixa restrição de alocação, seja referente aos totais investidos, instrumentos e imóveis passíveis de 
investimento, que compõem o que chamamos de ID e II, seja por regras que limitam aplicações e induzem determinadas condutas. ${ }^{2}$ Consideramos que as duas primeiras décadas marcaram um período de baixa restrição de alocação, haja vista o alto limite de investimento do total da carteira dos fundos de pensão a ser canalizado para o setor imobiliário. Já as três últimas décadas, quando foram introduzidas mudanças regulatórias sensíveis e cerceadoras do investimento dos fundos de pensão no mercado imobiliário comercial, apresentam-se como um período mais restritivo, com exceção da década de 2010-2020, que contou com uma elevada possibilidade de investimento em FIIs (10\%). Como veremos na próxima seção, essa autorização normativa foi pouco aproveitada pelos fundos de pensão estudados, uma vez que o canal indireto de investimento, em especial em FIIs, passou a ser mais usado somente a partir de 2019. ${ }^{3}$ Essa mudança, iniciada com a resolução $n^{\circ}$ 4.661, marca uma nova fase da atuação dos fundos de pensão (2020-2030) no mercado imobiliário comercial, a saber: uma fase centrada, basicamente, em instrumento financeiro gerido por intermediários financeiros.

A resolução $\mathrm{n}^{\circ} 4.661$ é um marco na política de investimento dos fundos de pensão brasileiros no mercado imobiliário comercial. Por impedir o investimento direto - que concentra 94\% do total investido atualmente no setor imobiliário pelos fundos de pensão (ABRAPP, 2019a), cerca de 30 bilhões de reais -, a normativa tem incitado grandes discussões entre os gestores envolvidos com a gestão dos recursos dos fundos de pensão. Somada ao cenário de baixa taxa de juros que vem pressionando a rentabilidade dos fundos de pensão - investidores importantes em títulos de dívida pública -, a proibição de ID foi analisada pelos entrevistados e pelos integrantes dos eventos assistidos durante a observação participante como uma medida perigosa para a manutenção das metas atuariais. Os gestores assinalaram que tal medida se enquadra em alto nível de descompasso com as práticas internas de gestão de portfólio adotadas por grandes fundos de pensão. Nesse sentido, observam-se movimentos, como formações de comissões e grupos de trabalho, que buscam reverter os efeitos da normativa, especialmente no que diz respeito à proibição do investimento direto em imóveis (CORAZZA, 2019; ABRAPP, 2019b).

2. As práticas de investimento giram em torno da confecção independente de laudos e avaliações de imóveis com periodicidade fixa, da busca por evitar a concentração de investimentos em um único imóvel ou veículo financeiro, entre outras. Notamos que esse cerceamento de práticas e condutas se tornou mais rigoroso durante as décadas analisadas.

3. Apesar de a análise de portfólio ter sido realizada para os anos de 2017 a 2019, os gestores de fundos de pensão entrevistados confirmaram que o canal direto sempre foi priorizado. O investimento indireto foi utilizado raramente; quando usado, os gestores afirmam que possuem o mesmo veículo na carteira até os dias atuais. 


\begin{tabular}{|c|c|c|c|c|c|}
\hline & $1988-1990$ & $1990-2000$ & $2000-2010$ & 2010- 2020 & $2020-2030$ \\
\hline 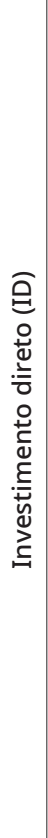 & $\begin{array}{l}\text { - Imóveis urbanos; } \\
\text { - Imóvel da patroci- } \\
\text { nadora; } \\
\text { - Participação } \\
\text { em sociedades } \\
\text { cujo intuito seja a } \\
\text { construção de um } \\
\text { empreendimento; } \\
\text { - Classificação: N/A; } \\
\text { - Limite de investi- } \\
\text { mento: } 20 \% \text {. }\end{array}$ & $\begin{array}{l}\text { - Imóveis urbanos; } \\
\text { - Imóvel da patroci- } \\
\text { nadora; } \\
\text { - Participação na } \\
\text { construção de } \\
\text { empreendimentos; } \\
\text { - Shopping Centers; } \\
\text { - Classificação: N/A; } \\
\text { - Limite de inves- } \\
\text { timento: 20\% (em } \\
\text { 1994) para 15\% (até } \\
\text { 2002). }\end{array}$ & $\begin{array}{l}\text { - Imóveis-desenvolvi- } \\
\text { mento: realização de } \\
\text { empreendimentos } \\
\text { imobiliários para } \\
\text { futura comerciali- } \\
\text { zação; } \\
\text { - Imóveis-renda: } \\
\text { investimentos } \\
\text { em imóveis ou na } \\
\text { realização de em- } \\
\text { preendimentos } \\
\text { imobiliários com a } \\
\text { finalidade de obter } \\
\text { rendimentos sob a } \\
\text { forma de aluguel ou } \\
\text { renda de participa- } \\
\text { ções; } \\
\text { - Classificação: } \\
\text { Segmento de } \\
\text { Imóveis; } \\
\text { - Limite de } \\
\text { investimento: } 8 \% \text { (ID } \\
\text { + II). }\end{array}$ & $\begin{array}{l}\text { - Empreendimentos } \\
\text { imobiliários; } \\
\text { - Imóveis para } \\
\text { aluguel e renda; } \\
\text { - Outros imóveis; } \\
\text { - Classificação: } \\
\text { Segmento de } \\
\text { Imóveis; } \\
\text { - Limite de investi- } \\
\text { mento: } 8 \% \text {. }\end{array}$ & $\begin{array}{l}\text { Em 2018, o ID } \\
\text { passou a ser } \\
\text { proibido (Resolução } \\
\text { CMN } \\
n^{\circ} 4.661 / 2018 \text { ) }\end{array}$ \\
\hline 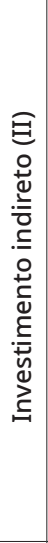 & - Não constava & $\begin{array}{l}\text { - Veículo financeiro: } \\
\text { FII; } \\
\text { - Classificação: Renda } \\
\text { Variável; } \\
\text { - Limite de inves- } \\
\text { timento: 50\% (em } \\
\text { 1994) para 10\% (em } \\
\text { 1996). }\end{array}$ & $\begin{array}{l}\text { - Imóveis-fundos: } \\
\text { investimentos em } \\
\text { quotas de FII; } \\
\text { - Classificação: } \\
\text { Segmento de } \\
\text { Imóveis; } \\
\text { - Limite de investi- } \\
\text { mento: } 8 \% \text { (ID + II); } \\
\text { - Veículo financeiro: } \\
\text { CRI e CCI; } \\
\text { - Classificação: Renda } \\
\text { Fixa; } \\
\text { - Limite de investi- } \\
\text { mento: } 20 \% \text {. }\end{array}$ & $\begin{array}{l}\text { - Veículo financeiro: } \\
\text { FII; } \\
\text { - Classificação: } \\
\text { Segmento Estrutu- } \\
\text { rado; } \\
\text { - Limite de investi- } \\
\text { mento: 10\%; } \\
\text { - Veículo financeiro: } \\
\text { CRI e CCI; } \\
\text { - Classificação: Renda } \\
\text { Fixa; } \\
\text { - Limite de investi- } \\
\text { mento: } 20 \% \text {. }\end{array}$ & $\begin{array}{l}\text { - Veículos financei- } \\
\text { ros: FII, FICFII, CCI } \\
\text { e LCI; } \\
\text { - Classificação: } \\
\text { Segmento Imobi- } \\
\text { liário; } \\
\text { - Limite de investi- } \\
\text { mento: } 20 \% \text {. }\end{array}$ \\
\hline 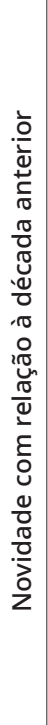 & $-N / A$ & $\begin{array}{l}\text { - Possibilidade de } \\
\text { investimento em } \\
\text { "Shopping Centers"; } \\
\text { - Consta, pela } \\
\text { primeira vez, FII } \\
\text { como possibilidade } \\
\text { de investimento; } \\
\text { - Estabelece limite de } \\
\text { aplicação em quotas } \\
\text { de um único FII e } \\
\text { para o mesmo imóvel } \\
\text { realizado por ID; } \\
\text { - Impõe a realização } \\
\text { de laudos de avalia- } \\
\text { ção dos imóveis em } \\
\text { carteira. }\end{array}$ & $\begin{array}{l}\text { - Criação do "Seg- } \\
\text { mento de Imóveis" } \\
\text { abrigando os ID e II } \\
\text { (FIIs somente); } \\
\text { - Redução abrupta } \\
\text { do limite de investi- } \\
\text { mento: } 8 \% \text { somado } \\
\text { ID e II. }\end{array}$ & $\begin{array}{l}\text { - Mantém no "Seg- } \\
\text { mento de Imóveis" } \\
\text { somente ID, com 8\% } \\
\text { de alocação máxima; } \\
\text { - FIIs passam a } \\
\text { compor um novo } \\
\text { segmento com maior } \\
\text { limite de alocação } \\
(10 \%) \text {. }\end{array}$ & $\begin{array}{l}\text { - Restrição do ID; } \\
\text { - Até 203o, os } \\
\text { fundos de pensão } \\
\text { devem se desfazer } \\
\text { dos imóveis ad- } \\
\text { quiridos por ID } \\
\text { através da venda } \\
\text { ou da formação de } \\
\text { FIIs com o próprio } \\
\text { portfólio; } \\
\text { - Possibilidade de } \\
\text { investimento em } \\
\text { FICFII; } \\
\text { - Diminuição do } \\
\text { limite de investimen- } \\
\text { to, considerando } \\
\text { a composição do } \\
\text { Segmento Imobiliá- } \\
\text { rio, que agora passa } \\
\text { a conter LCIs e CCIs. }\end{array}$ \\
\hline
\end{tabular}

Quadro 1. Enquadramento legal do investimento em mercado imobiliário realizado pelos fundos de pensão (1988-2020)

Fonte: elaborado a partir das Resoluções do Conselho Monetário Nacional (CMN), entre 1988 e 2020. 
No tocante à proibição de investimento direto em imóvel, parte dos entrevistados pontuou que a venda de um imóvel, a qual deve ser feita em até 12 anos após a publicação da normativa (até 2030), afetaria a rentabilidade da carteira imobiliária, devido à obrigação de liquidá-lo em um horizonte de curto prazo pré-estipulado (Entrevistado G, burocrata de alto escalão envolvido com a estruturação da resolução $\mathrm{n}^{\circ}$ 4.661). Contudo, os gestores de FIIs entrevistados ressaltaram que esse prazo é bastante razoável (Entrevistado I, CEO de consultoria imobiliária; Entrevistado O, sócio-diretor de gestora de ativos). Já a transferência dos imóveis para FIIs, possibilidade garantida pela resolução, parece ser a mais plausível para os gestores. Eles argumentaram, porém, que essa transferência envolve altos custos tributários, de estruturação e gestão do veículo financeiro ${ }^{4}$ (Entrevistado A, gestor de fundo de pensão privado; Entrevistado D, gestor de fundo de pensão estatal; Entrevistado F, gestora de fundo de pensão estatal; Entrevistado H, diretor de associação dos fundos de pensão; Entrevistado I; Entrevistado L, gestor-chefe de investimentos imobiliários de gestora de ativos brasileira). Além do argumento financeiro, os entrevistados reiteraram que a delegação da tomada de decisão com relação ao ativo imobiliário para um gestor terceiro é um custo de oportunidade muito grande (Entrevistado A; Entrevistados B, gestores de fundo de pensão estatal; Entrevistado D; Entrevistado J, gestor chefe de investimentos alternativos e crédito de gestora de investimentos brasileira). Assim, para driblar essa situação incômoda, um dos maiores detentores de estoque imobiliário entre os fundos de pensão tem optado por manter uma equipe interna não somente para selecionar os gestores de FIIs, como também para acompanhar esses intermediários e monitorar ativos. Acrescente-se que, tanto para gestores de FIIs envolvidos com a gestão de investimentos indiretos como para os gestores de fundos de pensão entrevistados, os maiores fundos de pensão possuem conhecimento suficiente para realizar investimentos imobiliários lucrativos a longo prazo, não sendo necessária, portanto, a chamada “delegação de carteira” para intermediários financeiros (Entrevistado G; Entrevistado H; Entrevistado J).

A resistência envolvendo a delegação para a indústria financeira também pode ser explicada pelas diferentes lógicas e horizontes de investimento mantidos pelos fundos de pensão e seus intermediários financeiros, principalmente os FIIs. Os fundos de pensão são instituições que prezam por retornos financeiros de longo prazo, realizando, em grande medida, investimentos em sintonia com a

4. Além dos encargos financeiros envolvidos no repasse desses bens para um gestor (Imposto sobre a Transmissão de Bens Imóveis e as tarifas cartoriais), os entrevistados admitem que os custos de administração e custódia desses FIIs são quase três vezes maiores que os custos atuais de gestão interna da carteira imobiliária. 
temporalidade mais longa dos seus passivos (pagamentos de aposentadoria). Por essa razão, há potenciais conflitos em termos de alinhamento de preferências (denominados conflitos agente-principal) com as instituições financeiras, cujo horizonte de investimento costuma ser mais circunscrito ao curto prazo.

Por fim, é necessário ressaltar que o processo de definição de agenda envolvendo essa alternância normativa ainda é pouco claro e, portanto, difícil de decifrar. Isso se deve ao fato de que as resoluções que regem as políticas de investimento dos fundos de pensão são feitas pelo Conselho Monetário Nacional, ${ }^{5}$ órgão pouco transparente quanto a suas pautas e a seu processo decisório. Os gestores de fundos de pensão entrevistados para essa pesquisa, assim como alguns gestores da indústria financeira, ressaltaram que as mudanças da resolução $\mathrm{n}^{0} 4.661$ que tratam sobre o investimento imobiliário foram inesperadas e que houve pouca participação dos principais interessados - isto é, dos fundos de pensão com as maiores carteiras imobiliárias - no processo de formulação dessa política. Um profissional ligado à estruturação da normativa comentou, em entrevista, que existiu um diálogo formal com os maiores fundos de pensão para sua construção; contudo, concernente ao investimento imobiliário, os membros do Conselho Monetário Nacional foram inflexíveis, tendo estipulado, mesmo com a resistência imposta no período de formulação da política, as restrições para o investimento direto. Para o burocrata e para o representante da ABRAPP (associação que representa os interesses dos fundos de pensão) entrevistados, o Conselho Monetário Nacional assumiu essa postura inflexível com o intuito de eliminar atitudes fraudulentas - envolvendo a posse de imóveis ilegais, superfaturados e associados a esquemas de corrupção - e de assegurar a liquidez das carteiras por meio da diversificação do e no investimento imobiliário. Quanto à participação da indústria financeira no processo de formulação da agenda, os entrevistados afirmaram que houve consultas aos principais agentes financeiros do país, como ANBIMA (Associação Brasileira das Entidades dos Mercados Financeiro e de Capitais), mas não adentraram em questões subjacentes ao tema, quando questionados.

Como sinalizam os resultados desta seção, há uma clara oposição ao investimento indireto em imóveis. Tal perspectiva demonstra que, no caso brasileiro, o investimento dos fundos de pensão via veículos financeiros lastreados em imóveis é um desafio que exige mais que readaptações legais. Nesse sentido, ainda é preciso compreender como se dará o investimento de fundos de pensão no mercado imobiliário comercial nos próximos anos, em cenário de queda de juros e de

5. Órgão que disciplina o sistema financeiro brasileiro e que possui como membros o atual Ministro da Economia (presidente do conselho), o Presidente do Banco Central e o Secretário Especial de Fazenda do Ministério da Economia. 
impedimento legal da compra direta de imóveis. A seção seguinte, além de abordar aspectos centrais da formação do portfólio dos 10 maiores fundos de pensão brasileiros, ressaltará se alguma mudança no padrão do canal de investimento (ID para II) e no perfil dos ativos investidos já pode ser notada entre os portfólios analisados.

\section{Caracterização do portfólio imobiliário dos fundos de pensão brasileiros}

Esta seção apresenta os resultados obtidos com a análise da carteira de investimento imobiliário dos 10 maiores fundos de pensão brasileiros nos anos de 2017, 2018 e 2019. Esse seleto grupo concentra mais da metade do total investido pelos fundos de pensão no mercado imobiliário atualmente (ABRAPP, 2019a). Foram examinados somente os investimentos enquadrados no segmento imobiliário, o que inclui investimentos diretos e investimentos indiretos (CRI, CCI e FII). As localizações dos empreendimentos e seus respectivos valores foram coletados nos relatórios anuais dos fundos de pensão e, adicionalmente, nos informes anuais e trimestrais dos FIIs investidos. Fontes complementares também foram utilizadas, como publicações nos sites dos fundos de pensão, no portal de notícias “Clube dos FIIs” e em imprensa especializada.

Exploramos, aqui, a evolução do portfólio imobiliário dos fundos de pensão no triênio selecionado (Quadro 2), com especial atenção para o perfil dos investimentos (localização e segmento) e para as diferenças entre o portfólio detido de forma direta e indireta. De início, destacamos que a investigação mostrou que os fundos de pensão investem majoritariamente através da via direta e que utilizam FIIs, em geral e quase exclusivamente, quando investem pelo canal indireto. Somente no ano de 2019 observamos o maior uso desse último canal, o que se verifica no valor total investido indiretamente, cerca de três vezes maior que o de 2018, bem como na quantidade de imóveis, aproximadamente $45 \%$ a mais que no ano anterior. Ao analisar, em específico, os investimentos indiretos em 2019, percebemos que, apesar do emprego de veículos financeiros ainda ser incipiente, esse portfólio é formado por ativos novos, ou seja, FIIs recém-adquiridos pelos fundos de pensão. Isso indica que os fundos de pensão estudados ainda não passaram por um processo de elaboração de FIIs para abrigar seus ativos adquiridos pela via direta - como mostra ser o movimento anunciado pelos entrevistados no pós-resolução $n^{0}{ }^{4} \cdot 661$; eles estão à procura de novas oportunidades no mercado imobiliário, operando, para tanto, com a estrutura de intermediários financeiros. Esses resultados visualizados reforçam que ainda há um longo processo de adaptação à nova regulação. Ao mesmo tempo, eles revelam que há um processo de busca de novos investimentos imobiliários não mais por via direta de aquisição - dados a estabilidade e o decrescimento do total de ativos imobiliários adquiridos por ela nos anos analisados - mas, sim, indireta, especificamente por meio de FIIs. 


\begin{tabular}{|c|c|c|c|c|c|c|c|c|c|c|c|c|}
\hline & \multicolumn{4}{|c|}{2017} & \multicolumn{4}{|c|}{2018} & \multicolumn{4}{|c|}{2019} \\
\hline & $\begin{array}{l}\text { Valor dos } \\
\text { imóveis } \\
\text { (BRL } \\
\text { bilhões) }\end{array}$ & $\%$ & $\begin{array}{l}\text { Total de } \\
\text { imóveis }\end{array}$ & $\%$ & $\begin{array}{c}\text { Valor dos } \\
\text { imóveis } \\
\text { (BRL } \\
\text { bilhões) }\end{array}$ & $\%$ & $\begin{array}{l}\text { Total de } \\
\text { imóveis }\end{array}$ & $\%$ & $\begin{array}{c}\text { Valor dos } \\
\text { imóveis } \\
\text { (BRL } \\
\text { bilhões) }\end{array}$ & $\%$ & $\begin{array}{l}\text { Total de } \\
\text { imóveis }\end{array}$ & $\%$ \\
\hline $\begin{array}{l}\text { Canal } \\
\text { direto }\end{array}$ & 23,1 & 89 & 323 & 77 & 23,8 & 92 & 303 & 76 & 23,9 & 77 & 285 & 68 \\
\hline $\begin{array}{c}\text { Canal } \\
\text { indireto }\end{array}$ & 2,8 & 11 & 94 & 23 & 2,2 & 8 & 94 & 24 & 7,0 & 23 & 136 & 32 \\
\hline Total Geral & 25,9 & 100 & 417 & 100 & 26,0 & 100 & 397 & 100 & 30,9 & 100 & 421 & 100 \\
\hline
\end{tabular}

Quadro 2. Investimentos realizados por meio dos canais direto e indireto (2017-2019)

Fonte: dados compilados pelos autores com base nos relatórios anuais de 2017, 2018 e 2019 dos 10 maiores fundos de pensão nacionais.

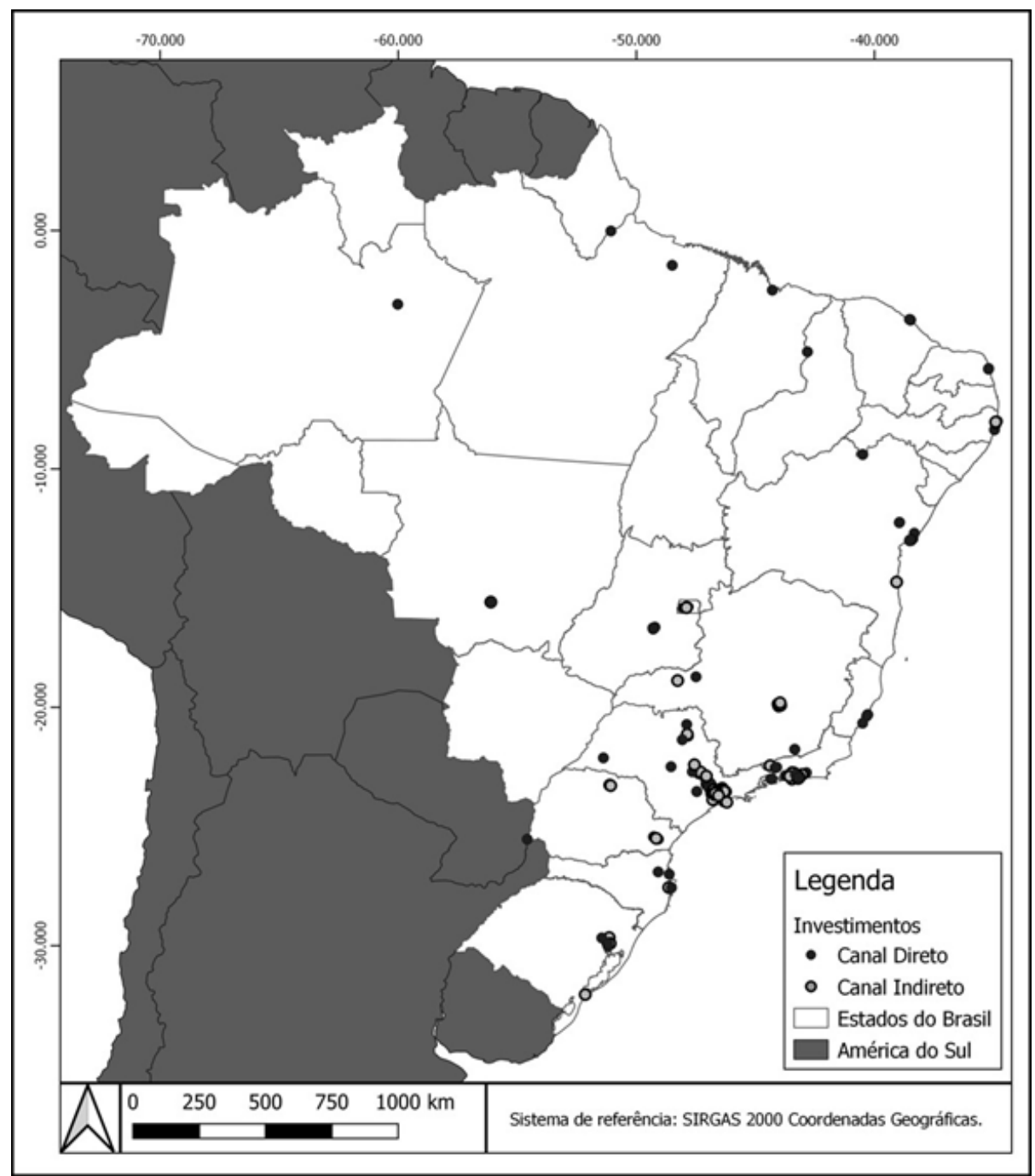

Figura 1. Localização dos empreendimentos imobiliários adquiridos pelos fundos de pensão por meio dos canais direto e indireto (2019)

Fonte: dados compilados pelos autores com base nos relatórios anuais de 2019 dos 10 maiores fundos de pensão nacionais. 
Analisando a localização dos empreendimentos adquiridos pelas duas vias ao longo dos anos (Figura 1), observamos um padrão de concentração nos estados de São Paulo e Rio de Janeiro e suas respectivas capitais e seus municípios adjacentes, ou seja, cidades com forte interdependência com a capital. Também encontramos um padrão que reforça uma tendência de concentração territorial do investimento: de 2017 a 2019, houve o aumento de cerca de 25\% (de 60 para 93) dos empreendimentos adquiridos por via indireta no estado de São Paulo, enquanto o estoque imobiliário obtido por via direta diminuiu, ao longo dos três anos, por volta de 15\% (de 117 para 99), seguindo a tendência verificada no país. Observando o padrão nos municípios paulistas, constatamos que 70, dos 93 empreendimentos adquiridos pela via indireta, estão na cidade de São Paulo. O restante está disperso pelo Estado, grande parte deles consistindo em empreendimentos logísticos. Já o desinvestimento em empreendimentos adquiridos pela via direta no estado de São Paulo atingiu, única e exclusivamente, imóveis localizados na capital. Uma análise mais detida nos permite concluir que o estado e a cidade de São Paulo são os únicos a apresentar um movimento mais dinâmico de venda e aquisição de imóveis. Isso indica, entre outras questões, o dinamismo do principal mercado imobiliário brasileiro.

Os resultados apresentados complementam as contribuições de Shimbo et al. (2021). Segundo os autores, as consultorias imobiliárias fomentaram um processo de reestruturação das carteiras imobiliárias dos fundos de pensão do país, fazendo com que eles direcionassem novos investimentos a outras localizações. Uma apreciação da concentração territorial dos investimentos dos fundos de pensão revela que o desinvestimento tem ocorrido, principalmente, em propriedades adquiridas pelo canal direto em São Paulo e que os novos investimentos imobiliários estão também localizados nesse Estado, mas, agora, a aquisição acontece via canal indireto.

Outro aspecto sensível ao entendimento da lógica de atuação dos fundos de pensão brasileiros no mercado imobiliário comercial refere-se à escolha de segmentos imobiliários. A segmentação contida no Quadro 3 foi criada no intuito de classificar os empreendimentos imobiliários por suas características mais marcantes. Empregamos tanto a ferramenta de georreferenciamento Google Earth para identificar a fachada dos empreendimentos quanto materiais secundários, como matérias de comunicação de compra e aquisição, disponíveis em mídias de notícias e sites dos fundos de pensão investigados. Com isso, identificamos que o padrão de investimento em segmentos é diferente entre os canais. No canal indireto, o segmento que mais concentra investimentos é o de agências bancárias, seguido pelo de logística. A predominância de investimentos em agências bancárias pode ser explicada pelo fato de que grande parte dos fundos de pensão analisados possui 
bancos como empresa patrocinadora. Como estratégia, o grupo opta pela criação de FIIs com as próprias agências bancárias, desmobilizando, assim, seu patrimônio em fundos de investimento (Entrevistados E, gestores de fundo de pensão privado). A incidência do setor de logística reforça os resultados a respeito da localização dos empreendimentos: quando optam por destinar recursos para outros municípios, principalmente para fora da capital paulista, os fundos se dirigem a municípios adjacentes que podem incrementar o funcionamento do setor de logística. Através do canal direto, por sua vez, percebemos uma concentração nos setores de escritório e shopping center. A preferência pela alocação nesses setores é justificada, pelos entrevistados, pela previsibilidade de bons resultados. É necessário ressaltar, ainda, a baixa alocação no setor residencial em ambos os canais, sendo que, pelo canal indireto, somente se investe em imóveis comerciais de uso misto, ou seja, que possuem lojas comerciais e residências no mesmo empreendimento.

\begin{tabular}{|l|c|c|}
\hline & Total de imóveis & Valor dos imóveis (BRL milhão) \\
\hline Canal Indireto & 136 & $\mathbf{7 0 2 4 , 0}$ \\
\hline Agência bancária & 44 & 376,1 \\
\hline Comercial e residencial (imóveis de uso misto) & 4 & 612,5 \\
\hline Escritório & 14 & 1664,5 \\
\hline Hotel & 1 & 63,0 \\
\hline Logística & 23 & 2450,8 \\
\hline Loja comercial & 12 & 340,9 \\
\hline Shopping center & 14 & 1510,8 \\
\hline Terreno & 18 & 5,2 \\
\hline Sem informação & 6 & $\mathbf{2 3 9 3 8 , 4}$ \\
\hline Canal Direto & 285 & 672,5 \\
\hline Agência bancária & 68 & 11367,0 \\
\hline Escritório & 94 & 31,7 \\
\hline Hospital & 1 & 873,7 \\
\hline Hotel & 7 & 1708,6 \\
\hline Logística & 11 & 310,4 \\
\hline Loja comercial & 13 & 7,5 \\
\hline Residencial & 17 & 8532,4 \\
\hline Shopping center & 50 & 348,2 \\
\hline Terreno & 13 & 68,2 \\
\hline Sem informação & 821 & 18,2 \\
\hline Outros & & 30962,4 \\
\hline Total Geral & 17 & \\
\hline
\end{tabular}

Quadro 3. Segmentos imobiliários das propriedades imobiliárias adquiridas pelos fundos de pensão (2019)

Fonte: dados compilados pelos autores com base nos relatórios anuais de 2019 dos 10 maiores fundos de pensão nacionais. 
Os dados apresentados sinalizam para uma mudança, ainda que incremental, no padrão de posse e condução dos investimentos imobiliários dos fundos de pensão. O possível aumento do uso do canal indireto, nos próximos anos, poderá acarretar um crescimento da indústria financeira especializada na gestão de ativos imobiliários e, também, na criação de novos instrumentos lastreados em rendas imobiliárias urbanas - segundo os entrevistados do setor financeiro, esse crescimento e profissionalização da indústria de FIIs, em especial, é uma vantagem da mudança de padrão de posse dinamizado pela resolução $\mathrm{n}^{\circ}$ 4.661. No entanto, por ser um movimento ainda incipiente, não se pode afirmar com precisão qual racionalidade prevalecerá nessa relação entre a indústria financeira e os fundos de pensão nem quais os impactos disso para o mercado imobiliário, ou seja, não há como mensurar se as preferências e horizontes de investimento dos fundos de pensão irão balizar as decisões feitas pelos gestores de FIIs ou, ao contrário, se haverá uma grande independência dos gestores de FIIs, no sentido de escolha das propriedades e da gestão dos empreendimentos. Além disso, como mostrou a análise do portfólio, por mais que haja uma resistência dos gestores dos fundos de pensão com relação ao canal indireto (aspecto trazido na seção anterior), os investimentos imobiliários continuam representando uma parcela significativa dos investimentos desses agentes. Dessa maneira, é provável que, para além da transferência dos imóveis que compõem a carteira imobiliária dos fundos de pensão para fundos imobiliários, esses investidores institucionais continuem a investir fortemente no segmento imobiliário, agora selecionando FIIs, em vez de propriedades. Essa mudança implicaria na perda de capacidade decisória dos fundos de pensão e, portanto, na possibilidade de direcionar sua trajetória de investimento.

\section{Implicações urbanas e econômicas: considerações finais}

Diferentes estudos trazem como contribuição secundária aos objetivos das pesquisas a participação de fundos de pensão como importantes agentes financeiros, responsáveis não só pelo financiamento urbano (de empreendimentos e infraestrutura), mas também como agentes de produção e consumidores finais de produtos urbanos. Apesar dessa gama de atuações que os fundos de pensão podem assumir no chamado "circuito imobiliário" (e seus diferentes impactos urbanos), aqui caracterizamos sua atuação como investidor financeiro que se dedica à extração de rendas de propriedades imobiliárias. Como mostrou este estudo, há, indiscutivelmente, um papel desempenhado por essa fração do capital na formação de cidades e na construção de metrópoles segregadas, já que grande parte do total destinado ao setor imobiliário pelos fundos de pensão brasileiros é dirigida para a compra de imóveis de alto padrão, em eixos urbanos extremamente valorizados das grandes metrópoles brasileiras. 
Analisar o padrão de investimento dos fundos de pensão evidencia não só o protagonismo assumido por esse investidor financeiro na configuração das metrópoles brasileiras, como também o poder exercido por esses atores na configuração dos mercados nacionais de propriedades comerciais. Como vimos, o investimento seletivo em propriedades de alto padrão, em segmentos específicos, como shoppings e escritórios, e nos principais eixos urbanos de São Paulo e Rio de Janeiro, especialmente, exige dos agentes envolvidos com a produção imobiliária (incorporadoras e construtores) e com a intermediação financeira (como FIIs) a oferta de imóveis e veículos que atendam ao perfil de investimento dos fundos de pensão. Potencialmente, esse direcionamento provocado por um dos maiores investidores institucionais brasileiros atualmente resulta em alterações nas dinâmicas de preço imobiliário e na oferta de bens e serviços dentro do espaço da metrópole.

Como discutido na segunda seção deste artigo, a possibilidade de os fundos de pensão exercerem seu papel como investidor financeiro no mercado imobiliário comercial ao longo das décadas (1990-2020) se alterou, passando de um período de afrouxamento (até os anos 2000) para um processo cada vez mais restritivo, culminando em um novo momento para suas práticas de investimento no mercado imobiliário comercial: agora centrado no investimento indireto e envolvendo intermediários da indústria financeira. Além da evolução das regulações e das pautas que circundam os atores envolvidos na formação desse novo direcionamento, duas tendências macroeconômicas recentes indicam que os fundos de pensão devem ganhar um peso maior no mercado imobiliário nos próximos anos, ainda que como investidores em veículos financeiros. Por um lado, as reformas no sistema de previdência aprovadas nos últimos anos nos níveis federal, estadual e municipal devem, com o devido tempo, favorecer a acumulação de recursos em entidades de previdência complementar, tanto privadas quanto públicas. Por outro, se for mantida a tendência de definição das taxas de juros em patamares historicamente reduzidos, os fundos de pensão deverão canalizar parcela relevante dos seus recursos sob gestão para investimentos alternativos, como imobiliário e infraestrutura. Nesse contexto, se a resolução $n^{\circ} 4.661$ não for revogada ou alterada, os investimentos no imobiliário serão realizados por intermediários da indústria financeira.

Um dos grandes incentivos trazidos pelos órgãos reguladores e pela indústria financeira envolvida com os Fundos de Investimento Imobiliário para o investimento indireto gira em torno do fato de que esses veículos permitiriam uma melhor distribuição espacial e em segmentos de investimento, possibilitando, assim, uma carteira mais diversificada e segura aos fundos de pensão. Porém, este artigo demonstra que tais premissas não se encontram em conformidade com a atual configuração dos investimentos dos fundos de pensão brasileiros. Os investimentos 
indiretos, assim como diretos, continuam concentrados, majoritariamente, nos Estados que possuem economias e mercados imobiliários mais dinâmicos (São Paulo e Rio de Janeiro); e são canalizados para segmentos imobiliários cuja função e uso da propriedade imobiliária favorecem um perfil de inquilino muito restrito prioritariamente, grandes empresas nacionais ou estrangeiras em contratos de locação de longo prazo. Sem entrar no mérito das motivações dos grupos de interesse envolvidos com a referida resolução, é muito provável que sua recente aprovação acarrete, no médio e longo prazo, um crescimento da indústria financeira e de seu poder em direcionar recursos segundo critérios de risco e retorno que exacerbam assimetrias territoriais.

Convém assinalar, por fim, que a compreensão da atuação de investidores institucionais como fundos de pensão suscita diferentes questões do ponto de vista de políticas públicas. De uma parte, é preciso repensar a pertinência da resolução $\mathrm{n}^{\circ}$ 4.661, diante das evidências de que os maiores fundos de pensão possuem capacidade gerencial para fazer os investimentos sem o intermédio (e custos elevados) da indústria financeira. De outra, é conveniente ter maior clareza da capacidade desses atores em extrair rendas imobiliárias por meio de diferentes canais de investimento, a fim de, a partir disso, direcionar políticas públicas especificas que lidem melhor com os impactos urbanos gerados pela atuação deles.

\section{Referências}

AALBERS, M. Financial geography II: financial geographies of housing and real estate. Progress in Human Geography, v. 43, n. 2, p. 376-387, maio de 2019.

ABRAPP. ASSOCIAÇÃO BRASILEIRA DAS ENTIDADES FECHADAS DE PREVIDÊNCIA COMPLEMENTAR. Consolidado estatístico: uma fotografia mensal do setor. 2019a. Disponível em: http://www.abrapp.org.br/Consolidados/Consolidado\%20 Estat\%C3\%ADstico_10_2019.pdf. Acessado em março de 2020.

Grupos de trabalho da Abrapp avançam em propostas e soluções para o sistema. A!contece, edição 20 de Setembro de 2019. 2019b. Disponível em: https://mailchi. $\mathrm{mp} / 3119$ ecfda1e5/acontece-grupo-de-trabalho-da-abrapp-prepara-estudos-e-propostas-para-nova-previdncia?e=9docc53d4b. Acessado em 28 de julho de 2020.

CATTANEO PINEDA, R. A. Los fondos de inversión inmobiliaria y la producción privada de vivienda en Santiago de Chile: ¿Un nuevo paso hacia la financiarización de la ciudad? EURE, v. 37, n. 112, p. 5-22, set. 2011.

CLARK, G. Pension fund capitalism. Oxford: Oxford University Press, 2000.

CLARK, G. L.; MONK, A. H. B. Institutional investors in global markets. Oxford: Oxford University Press, 2017. 
CMN. CONSELHO MONETÁRIO NACIONAL. Resolução CMV nº 4.661, de 25 de maio de 2018. Dispõe sobre as diretrizes de aplicação dos recursos garantidores dos planos administrados pelas entidades fechadas de previdência complementar. Diário Oficial da União, 29 de maio de 2018: Seção 1, p. 22-24.

CORAZZA, M. Entra na pauta a revisão da 4.661. Revista da Previdência Complementar Fechada, v. 38, n. 424, p. 71-76, setembro/outubro 2019.

FIX, M. São Paulo cidade global: fundamentos financeiros de uma miragem. São Paulo: Boitempo, 2007.

HAGERMAN, L.; HEBB, T. Balancing risk and return in urban investing. In: CLARK, G. L.; DIXON, A. D.; MONK, A. H. B. Financial risk management: from the global to the local. Oxford: Oxford University Press, 2009. p.189-208.

HALBERT, L.; ATTUYER, K. The financialization of urban production: conditions, mediations and transformations. Urban Studies, v. 53, n. 7, p. 1347-1361, jan. 2016.

HALBERT, L. Les acteurs des marchés financier's font-ils la ville? Vers un agenda de recherche. EspacesTemps.net Revue indisciplinaire de sciences sociales. Peer review, 2013. Disponível em: https://www.espacestemps.net/en/articles/les-acteurs-des-marches-financiers-font-ils-la-ville-2/. Acessado em agosto de 2020.

HALBERT, L.; HENNEBERRY, J.; MOUZAKIS, F. The financialization of business property and what it means for cities and regions. Regional Studies, v. 48, n. 3, p.547-550, mar. 2014.

HEBB, T.; SHARMA, R. New finance for America's cities. Regional Studies, v. 48, n. 3, p. 485500, dec. 2013.

HENNEBERRY, J.; MOUZAKIS, F. Familiarity and the determination of yields for regional office property investments in the UK. Regional Studies, v. 48, n. 3, p. 530-546, fev. 2013.

KLINK, J.; BARCELLOS, M. Financeirização: conceitos, experiências e a relevância para o campo do planejamento urbano brasileiro. Cadernos Metrópole, v. 19, n. 39, p. 379-406, maio/ago. 2017.

LEYSHON, A.; THRIFT, N. The capitalization of almost everything: the future of finance and capitalism. Theory, Culture \& Society, v. 24, n. 7, p. 97-115, dec. 2007.

LIZIERI, C.; PAIN, K. International office investment in global cities: the production of financial space and systemic risk. Regional Studies, v. 48, n. 3, p. 439-455, jan. 2013.

ROLNIK, R. Late neoliberalism: the financialization of homeownership and housing rights. International Journal of Urban and Regional Research, v. 37, n. 3, p. 1058-1066, may, 2013.

SANFELICI, D. Investidores financeiros no mercado imobiliário comercial: racionalidades decisórias e repercussões urbanas. In: SERPA, C.; CARLOS, A. F. Geografia Urbana: Desafios Teóricos Contemporâneos. 1 ed. Salvador: EDUFBA, 2018. p. 215-236.

SHIMBO, L.; SANFELICI, D.; MARTINES-GONZALEZ, B. Consultorias imobiliárias internacionais e racionalidade financeira na avaliação e gestão de imóveis em São Paulo. EURE, v. 47, n. 140, p. 221-242, jan. 2021.

THEURILLAT, T.; CORPOTAUX, J; CREVOISIER, O. Property sector financialization: the case of swiss pension funds (1992 - 2005). European Planning Studies, v. 18, n. 2, p. 189-212, fev. 2010. 
THEURILLAT, T.; CREVOISIER, O. Sustainability and the anchoring of capital: negotiations surrounding two major urban projects in Switzerland. Regional Studies, v. 48, n. 3, p. 501-515, mar. 2013.

VAN LOON, J.; AALBERS, M. How real estate became 'just another asset class': the financialization of the investment strategies of Dutch institutional investors. European Planning Studies, v. 25, n. 2, p. 221-240, jan. 2017.

WIJBURG, G.; AALBERS, M. The internationalization of commercial real estate markets in France and Germany. Competition \& Change, v. 21, n. 4, p. 301-320, jun. 2017. 


\section{Maira Magnani}

Mestranda, com bolsa FAPERJ nota 10, no Programa de Pós-Graduação em Geografia da Universidade Federal Fluminense (UFF). Possui graduação nos cursos de Ciências e Humanidades (2017) e Políticas Públicas (2018) pela Universidade Federal do ABC (UFABC). Em 2020, teve a pesquisa de mestrado selecionada para receber a bolsa de estudos do Programa América Latina de Suporte à Bolsas de Estudos de Pós-Graduação (Latin America Program Graduate Student Fellowship Support) do Lincoln Institute of Land Policy. Desenvolve pesquisas no campo da geografia econômica sobre a atuação dos fundos de pensão brasileiros no mercado imobiliário comercial. Atualmente, participa de projeto de pesquisa sobre a atuação de investidores financeiros e corporativos no mercado imobiliário comercial brasileiro. É membro do Núcleo de Pesquisas sobre Pactos Políticos-Territoriais e Desenvolvimento (NUPACT).

Email: mairamagnani@uol.com.br

ORCID: 0000-0002-0074-5622

Contribuição de autoria: conceituação; análise formal; investigação/pesquisa; metodologia; escrita - primeira redação.

\section{Daniel Sanfelici}

Professor do Departamento de Geografia e do Programa de Pós-Graduação em Geografia da Universidade Federal Fluminense. Possui graduação em Geografia pela Universidade Federal do Rio Grande do Sul (2005), Mestrado (2009) e Doutorado (2013) em Geografia Humana pela Universidade de São Paulo. Realizou estágio de Doutorado no Center for Place, Culture and Politics (CUNY/Graduate Center) entre agosto de 2010 e junho de 2011, quando foi bolsista do convênio Capes/Fulbright. Foi pesquisador 
de pós-doutorado na Universidade Federal Fluminense em 2014 (Capes/PNPD) e no Laboratoire Techniques, Territoires et Sociétés (LATTS), Université Paris-Est, em 2015 (Capes). Desenvolve pesquisas nas áreas de estudos urbanos e geografia econômica, com ênfase nos seguintes temas: atores e dinâmicas do mercado imobiliário urbano, políticas de ordenamento territorial, fontes e estruturas de financiamento à produção imobiliária urbana e modelos de governança das cidades. Atualmente, desenvolve projeto de pesquisa sobre a atuação de investidores institucionais no mercado imobiliário comercial brasileiro. É membro da comissão editorial da revista GEOgraphia (UFF) e coordenador do Núcleo de Pesquisas sobre Pactos Políticos-Territoriais e Desenvolvimento (NUPACT).

Email: danielsanfelici@gmail.com

ORCID: 0000-0002-8292-5503

Contribuição de autoria: obtenção de financiamento; investigação/pesquisa; administração do projeto; supervisão/orientação; escrita - primeira redação; escrita - revisão e edição.

\section{Guilherme A. Muniz Filho}

Graduando em Geografia pela Universidade Federal Fluminense (UFF). Participou do Programa Institucional de Bolsas de Iniciação à Docência (Pibid), promovido pela Coordenação de Aperfeiçoamento de Pessoal de Nível Superior (Capes). Desenvolve pesquisa na área de Geografia Humana, com ênfase em Geografia Econômica. Atualmente, é bolsista de Iniciação Científica do Conselho Nacional de Desenvolvimento Científico e Tecnológico (CNPq) e membro do Núcleo de Pesquisas sobre Pactos Políticos-Territoriais e Desenvolvimento (Nupact).

Email: guilhermefilho@id.uff.br

ORCID: 0000-0003-1649-8328

Contribuição de autoria: curadoria de dados.

Submissão: 22 de dezembro de 2020.

Aprovação: 30 de março de 2021.

Como citar: MAGNANI, M.; SANFELICI, D.; MUNIZ FILHO, G. A. Os investimentos dos fundos de pensão brasileiros no mercado imobiliário comercial: uma análise do portfólio imobiliário e seu padrão territorial. Revista brasileira de estudos urbanos e regionais. v. 23, E202114, 2021. DOI 10.22296/2317-1529.rbeur.202114

Artigo licenciado sob Licença Creative Commons CC BY 4.0. https://creativecommons.org/licenses/by/4.o/deed.pt_BR 